\title{
Slide presentations as an object of research: definition, features, history and criticisms
}

abstract The aim of this paper is to discuss the slideshow, together with its history and, by means of a bibliographical review, opinions that have been written about it. Due to their great popularity, slideshows have been widely adopted by very different social groups, whenever professionals from all fields have felt the need to represent information through graphic language. It is our belief that studies in the field of design have not focused enough attention on slide presentations as a research object, and therefore, it is our intention to set down a number of points that could encourage further research possibilities.

slide presentations, history, criticism

\section{Introduction}

It is estimated that at any given second, 350 slide presentations are being displayed throughout the world (Parks, 2012), and that this technology is used by at least 750 million people, a figure which alone represents the number of PowerPoint users (Foley, 2010). These data reveal the presence of this technology within many spheres of our lives: school, work and other social interactions.

The present article has adopted a bibliographical approach in order to discuss the slide presentation as an object of study. First, we concentrate on its definition and features, together with the implications for the perception and use of this artefact. Following on, we then discuss some key points related to the history of the slide presentation and how this has influenced its current form. Finally, we indicate the current state of research into slideshows and present a number of controversial opinions regarding this subject in the field of design.

The market is already aware of the need for more satisfying and accurate interchanges of information, and many specialized studios that work with presentation design are beginning to emerge. This trend reinforces the reasons why we must concentrate more efforts on this subject, not only with more studies, but also within our own practices as teachers, professionals or even conference participants.

\section{About slide presentations}

The term 'digital slide presentations' was coined by Mollerup (2011), and is a very precise definition of what we are discussing: digital files used to display data in sequences of slides, created with specific software for this exact purpose. The word 'digital' differentiates the artefact we are addressing herein from sequences of physical slides 
(produced with photographic processes).

The most popular software for creating slides is Microsoft PowerPoint, so much so that the term 'Powerpoint' has become a synonym for slide presentation.

Digital slide presentations, or slideshows, are not only used to present data during lectures, but also for other purposes, such as sharing contents through email or websites, and printed as handouts. These different uses and materials are contrary to the idea that the slide presentation is just a media.

Vieira (2011) considers it a genre, and its widespread use within unlikely contexts represents a change in the rules of genres. Yates \& Orlikowski (2007) state that the genre of letters, for example, has never been used for so many different purposes or media as slideshows. Farkas (2006) insists that there is a wide variety of slideshow genres because they are used for a variety of social interactions (such as scientific presentations or welcome speeches) and that each genre has a particular vocabulary and a greater or lesser depth of content.

To opt for a slide presentation instead of a printed poster, a report or a chalkboard usually represents the need to present data to a group of people in a synthesized, customized manner with the aid of visual language. However, as Parker has warned, it could also be that slideshows have become so popular that their use is no longer even questioned, and to appear at a meeting without a slide presentation would be "unwelcome and vaguely pretentious, like wearing no shoes" (Parker, 2001:2)

In terms of use, one of the main features of the slide presentation is that it is multimedia, since it can display video, text, music and pictures in a multimodal manner, and which is comprehended through listening and watching. However, despite this diversity of use, slideshows are not interactive when we consider the unfortunate role of the lecture audience, since the power of decision is totally in the hands of the lecturer.

With regard to syntax, slide presentations normally contain many titles (Vieira, 2011), because content is divided up, due to the limited space available for displaying information, and the need to separate information onto smaller, coordinated levels. When we analyse slides more closely, we will see that not all the information it displays is mentioned during a lecture or is part of the main message contained within the slide. Some titles are only used in order to organize the comprehension of the slideshow as a whole. Another assumption by Vieira (2011) is that slideshows rely on multiple methods of representing the graphic language, and the space of the slide is explored in non-linear manners, which extend further than the usual verbal arrangements.

Figure 1.

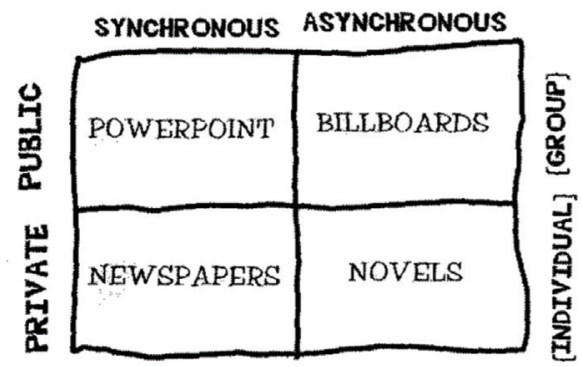


The presentation component of slide presentations gives it a sense of being a social activity. For Vieira (2011), as companies have changed to a democratic, participative approach with regard to their employees, slide presentations have replaced reports as a medium of sharing information. This is because reading, in the words of Gold (2002), is synchronous, which means that it is consumed by the audience at the same time, much like newspapers and webchats, and is also public and collective, since it is read by a group, unlike of a book, for example (Figure 1).

The format of slide presentations comes from the corporate environment, and Yates \& Orlikowski (2006) address certain practices such as the organization of information in bullet points, and the progressive display of information to overhead transparencies used before the advent of digital slides.

\section{The origin of digital slideshows}

Although they only became widely known during the gos, software for creating slides go back to the beginning of the 80 s. It is not easy to be precise about which was the first software able to generate slides, since slides had to be printed, and so any word processor was able to produce slides.

The HP 3000 computers may have had the pioneering technology concerned with the production of multimedia presentation graphics, because they had a business graphic suite that allowed the design of slides with text, charts and pictures in 1983, even though each part needed to be produced in separate software and merged in another program for the printing (Dolan, 1983).

Also in 1983, VCN Execuvision was released for PC and possessed a much more complex interface (Figure 2). This software provided ten different choices of fonts (while the PC had just two), permitted the use of animation techniques and gave form to the slideshow as a whole, with either manual or automatic control of the pace of slides (Toong \& Gupta, 1984). This was a very useful feature to test the slideshow, but at that time it was not possible to project it, as video projectors were not yet being used.
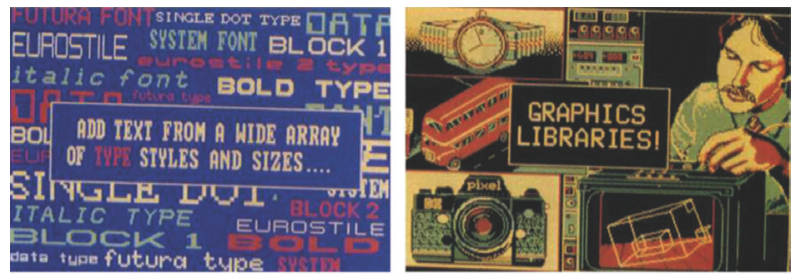

Figure 2.

Toong \& Gupta (1984: 383), Some examples of VCN Execuvision slides.
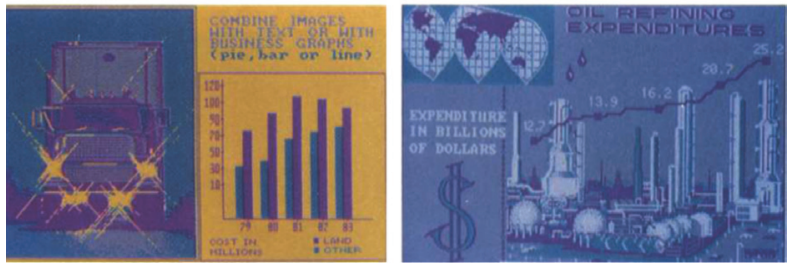
But the most popular, well-known tool of this kind was yet to come: Microsoft PowerPoint was only released in 1987 and its great acceptance was not due to a lack of other options. Gaskins (2007) states that the Microsoft marketing department had identified more than 30 similar programs one year before its launch. For Gaskins, PowerPoint was a success because it was a pioneer in the new generation of computers (with a userfriendly interface), it focused on slide visuals and it presented fewer problems than other programs (Gaskins, 2007).

PowerPoint was so successful that the second edition was released the following year, and in colours. It should be noted that it was only in 1990 that a version of this software was made available for Windows, since it had only previously been available for Macintosh.

The advantages of digital slide presentations in relation to $35 \mathrm{~mm}$ slides was mainly in the price, because physical slides had to be produced in a professional studio. The quality of the images was also much better when compared to overhead transparencies, which usually presented marks from the photocopier and became scratched through use. Digital slides were more convenient because they had been produced and were designed by the speaker her/himself.

PowerPoint is still the most important software of the category and the estimated statistics surrounding the product are surprising: it has been installed on around 1 billion computers and has 95\% of the market share (Parks, 2012). Yet, there are some similar programs that are also known, such as Keynote, from Apple, and Impress, which is free, just like other websites that generate multimedia presentations, such as Google Drive and SlideRocket.

\section{Studies and criticisms}

Due to the importance and the broad use of slide presentations in the routines of people from many different fields, it has become the focus of interest in analysis and research. But it would appear that designers are not concerned about this kind of graphic document, or indeed aware of the multiple nature of analysing it as an object of scientific study. Slideshows are one of the only graphical documents designed by the general public, and software like PowerPoint are the main programs they use for such graphical arrangements and creations, using it to design printed objects like posters or cards.

One of the main critics of PowerPoint (although most of his points may be generalized to other programs) is Edward Tufte, who is not actually a designer, but studies and produces content on the field. He was concerned about what he calls a "cognitive style of PowerPoint", which is the name of a booklet he published. Tufte believes that the software has such a strong influence over the arrangement of information that it undermines the message, such as organizing all the content in hierarchical lists and the forced sequentiality, over which the audience has no control (Tufte, 2008).

While lots of people agree with his comments, others have stood against Tufte's opinions, suggesting that Tufte has misled the focus of the debate: they believe the problem is based in the bad use of the tool. For them, PowerPoint is reinforced as being just a tool used by people with little design/communication knowledge and ability and Farkas (2006) defends that most of the problems would not occur in the hands of an experienced user.

Yates and Orlikowski (2006) believe that Tufte does not differentiate the genre and purpose of slideshows from reports when he claims that slides do not have enough 
information, because slideshows are meant for presentation and the information needs to be acquired by listening and watching, while reports on the other hand, should contain all the information.

Doumont (2005) accuses Tufte's booklet of being repetitive in his criticisms on PowerPoint, and that it is commercial rather than scientific (since Tufte published it as a booklet, not as a paper). He also claims that it is inaccurate, as Tufte does not differentiate between the software, the presentation technology and the slideshows. He also defends that the hierarchical lists are not exclusive to slides, and appear in many types of documents. In the end, he states that Tufte is wrong when he says that slides have a low resolution, which he compares to the resolution of paper and states that maybe he had the intention of saying that the canvas of slides is limited in comparison to a sheet of A4 paper.

Apart from these arguments, Tufte's warning on the subject was very important in order to bring about reflections on the indiscriminate and inadequate use of this kind of tool and the need to involve information design in the presentations.

When we focus our attention onto scientific production and research on slideshows, we notice that they mainly concentrate on the areas of engineering, computing and applied psychology. There are a few in the area of education and letters, but names from design are more rare, such as David Farkas. He calls for more diversity than just studies in the educational environment, like the business area, and a more solid approach to research with the standardization of terms and empirical studies, and less use of personal opinions (Farkas, 2006).

If we examine Brazilian scientific production in design published on the proceedings of events, there is almost no work regarding this subject, even in graphic design and information design publications (except for our own, published last year).

\section{Conclusion}

We have seen that slide presentations are used by about ten per cent of the world's population and are multimedia, multimodal, digital and are not only used for displaying information to a great amount of people. We also understand their social character and format when we investigate the historical roots in corporative presentations.

We have also discussed the arrangement of scientific studies on this subject, and how the field of design is not yet inserted into this circuit. In general terms, although there is a proliferation of reviews on many themes concerning slide presentations (programs, their use and effectiveness), many are opinionative, much like Tufte's, a respected information design theorist.

This article aims to stimulate more research in the field of design concerning slide presentations, by showing its relevance, wide use, controversies and problems from within a bibliographical approach.

\section{References}

Dolan, R. (1983). Editorial. Hewlett Packard Journal, vol. 34, no.1, pp. 2.

Doumont, J. (2005). The cognitive style of PowerPoint: Slides are not all evil. Technical Communication, v. 52, no. 1, pp. 64-70. 
Farkas, D. (2006). Toward a better understanding of PowerPoint deck design. Information Design Journal + Document Design, vol. 4, no. 2, pp. 162-171.

Foley, M. (2010). About that 1 billion Microsoft Office figure... ZDNet. Available: zdnet.com/blog/ microsoft/about-that-1-billion-microsoft-office-figure/6555 [10 Jan 2014].

Gaskins, R. (2012). Sweating Bullets - Notes about inventing PowerPoint. San Francisco: Vinland Books.

Gold, R. (2002). Reading PowerPoint. In: ALLEN, N. (ed.), Working with words and images: New steps in an old dance, pp. 256-270. Westport: Ablex.

Mollerup, P. (2011). PowerNotes: slide presentations reconsidered. [E-book]. Melbourne: IIID - International Institute for Information Design. Available: hdl.handle.net/1959.3/191214 [7 Jun 2011]

Parker, I. (2001). Absolute PowerPoint: can a software package edit our thoughts? The New Yorker. Annals of Business. Available: newyorker.com/archive [3 Mar 2013].

Parks, B. (2012). Death to PowerPoint! BusinessWeek. Available: businessweek.com/ articles/2012-08-30/death-to-powerpoint [10 Jan 2014].

Toong, H.; Gupta, A. (1984). A new direction in personal computer software. The Institute of Electrical and Electronics Engineers, vol.72, no.3, pp. 377-388.

Tufte, E. (2008). The cognitive style of PowerPoint: Pitchin Out Corrupts Within. Connecticut: Graphics Press.

Vieira, A. (2011). Retórica e Multimodalidade do PowerPoint Educativo. Non-published PhD Thesis. Letters Department. UFPE: Recife - Brazil.

Yates, J. and Orlikowski, W. (2006). The PowerPoint presentation and its corollaries: How genres shape communicative action in organizations. In: Zachry, M. and Thralls, C. (ed.) The cultural turn: Communicative practices in workplaces and the professions. Amityville, NY: Baywood Publishing. 
